\title{
Sensitivity of Sverdrup transport to surface wind products over the tropical North Pacific Ocean
}

\author{
Hui Zhou ${ }^{1,2,3}$ (1) Xueqi Liu ${ }^{1,3} \cdot$ Peng Xu ${ }^{4}$ \\ Received: 25 May 2018 / Accepted: 4 March 2019 / Published online: 15 March 2019 \\ (C) The Author(s) 2019
}

\begin{abstract}
This study investigates the sensitivity of the Sverdrup transport to the NCEP/NCAR, ERA-Interim, CCMP, and QSCAT wind products over the tropical North Pacific Ocean during the period of 2000-2008. Our analyses show that all of the S-E transports in the reanalysis/analysis winds are northward in the band of 7-9 $9^{\circ} \mathrm{N}$ except the QSCAT wind, which produces more realistic southward transport as shown in the meridional geostrophic transports (MGTs) calculated from WOA13 and Argo data. At 24 $\mathrm{N}$, high-resolution wind products can better estimate the meridional transport in this region. At $8^{\circ} \mathrm{N}$, although the CCMP has the same high resolution as the QSCAT, it fails to produce more realistic ocean circulation just as the coarse resolution wind products do there. The unrealistically large wind stress curl and small zonal wind stress in winter in reanalysis/analysis wind products account for this discrepancy with the QSCAT. This discrepancy also suggests that the model physics used in these reanalysis wind products is deficient in depicting the ocean circulation in this region, where the ocean fronts and eddy activity are both active.
\end{abstract}

Keywords Wind stress curl $\cdot$ Wind stress $\cdot$ Sverdrup balance $\cdot$ El Niño $\cdot$ ENSO $\cdot$ Ocean fronts $\cdot$ Meso-scale eddy

\section{Introduction}

Traditionally, our understanding of the mean meridional transports of the ocean is based on Sverdrup theory (Sverdrup 1947), which obtains the meridional transport of the wind-driven ocean circulation by integrating the wind stress curl (WSC) without detailed information of the oceanic baroclinicity under a linear dynamic assumption. It describes a simple yet powerful balance between the WSC and the depth-integrated meridional transport in the interior ocean. It has been prominent in diagnoses of the

Responsible Editor: Bruno Castelle

Hui Zhou

zhouhui@qdio.ac.cn

1 CAS Key Laboratory of Ocean Circulation and Waves, Institute of Oceanology, and Pilot National Laboratory for Marine Science and Technology (Qingdao), Chinese Academy of Sciences, 7 Nanhai Road, Qingdao 266071, China

2 Center for Ocean Mega-Science, Chinese Academy of Sciences, Qingdao Collaborative Innovation Center of Marine Science and Technology, Qingdao, China

3 University of Chinese Academy of Sciences, Beijing 100049, China

4 Qingdao Jin Guling School, Qingdao, China tropical circulation in the Pacific Ocean, where the ocean state and its interaction with the atmosphere play an important role in the magnitude and time evolution of El Niño Southern Oscillation (ENSO) events and global climate system (Jin and Neelin 1993; Cane 1998; Meehl et al. 2001; Hu et al. 2015; Zhou et al. 2018). However, it has been difficult to provide strong observational evidence for its validity due to a lack of long-term ocean observations.

Early studies (Spillane and Niiler 1975; Wyrtki 1975; Meyers 1980) have shown that the Sverdrup transport calculated from 2 to $5^{\circ}$ latitude grid wind stress data does not account for the Pacific North Equatorial Countercurrent (NECC). They attribute the discrepancy to strong vorticity advection and lateral mixing near the current boundaries, where the meridional shear is large. Recent studies also suggest that Sverdrup transports are found to underestimate the mean gyre circulation of the low-latitude northwestern Pacific Ocean significantly based on comparisons with Argo data collected in the past 10 years or so (Zhang et al. 2013; Yuan et al. 2014; Yang and Yuan 2016), and the difference has been attributed to oceanic nonlinearity. However, the wind stress data used in above studies are all coarse resolution (zonal resolution $>2^{\circ}$ ), which cannot resolve small structures of wind stress and wind stress curl in this region. Landsteiner et al. (1990) compared three different wind products in 
estimation of the Sverdrup transport in the tropical Pacific Ocean, and they concluded that detailed and accurate simulation of the general circulation in the tropical Pacific is limited more by the uncertainties in estimates of the surface wind stresses than by deviations from Sverdrup balance. Kessler et al. (2003) argued that the WSC structure in equatorial eastern Pacific is crucial in realistic estimation of ocean circulation there.

So, reliable knowledge of the wind stress fields and WSC at the sea surface is very important for understanding the ocean circulation in tropical North Pacific. Errors in wind stress forcing affect not only the interior ocean but the western boundary as well, since systematic errors in the wind field accumulate toward the west. This could lead to considerable uncertainty in model studies of higher-order processes such as meridional heat transport, which depend on accurate simulation of both interior and western boundary currents. However, considerable uncertainties exist in estimating the WSC due to inadequate temporal and spatial sampling of the observations, which causes substantial discrepancies in different wind stress analyses and thus in ocean meridional transport estimates and model simulations (Harrison 1989; Landsteiner et al. 1990; Chen 2003; Kessler et al. 2003).

The commonly used sea surface wind products can be divided into two types, one is observational data and the other is reanalysis/analysis data. For the observational wind products, the in situ observations have been constrained by limited sampling in both space and time. Remote sensing of sea surface winds has been widely used, and these data provide high spatial and temporal resolution, near global coverage and extensive validation. In general, they agree reasonably well with in situ observations and surface analysis fields, but some biases are found especially in regions with strong sea surface currents (e.g., Bentamy et al. 1999; Ebuchi 1999; Kelly et al. 2001; Meissner et al. 2001; Ebuchi et al. 2002; Bourassa et al. 2003; Curry et al. 2004; Yuan 2004; Chelton and Freilich 2005). Moreover, the temporal record of remote sensing wind data is less than 30 years, which is not suitable for long-term climate study.

For this reason, over the past decade, reanalysis/analysis wind products have found widespread application in many areas of research ranging from studies of climatic trends and climate modeling (Bromwich and Fogt 2004; Decker et al. 2012). These products are generated by the assimilation of observational data over a given period of time, which is advantageous in climate studies because of their high resolution in space and time with long-term range. However, the accuracy of these fields remains dependent to a large extent on the model physics.

In this study, we first compare the WSCs calculated from observational and reanalysis/analysis wind products, and then we investigate the sensitivity of Sverdrup transport to these wind products over the tropical North Pacific Ocean. In the following section, we describe the method and sea surface wind datasets used in this study. In section 3, we compare the WSC among different wind products. The Sverdrup circulation and its sensitivity to different wind products are discussed in section 4. Summary and discussions are given in section 5 .

\section{Data and methods}

\subsection{Surface wind data}

Monthly means of gridded $10 \mathrm{~m}$ wind velocity data used in this study comes from four sources: National Centers for Environmental Prediction/National Center for Atmospheric research (NCEP/NCAR) (http://www.esrl.noaa.gov/psd/data/ gridded/data.ncep.reanalysis.html), ERA-Interim (http:// www.esrl.noaa.gov/psd/data/gridded/data.erainterim.html), Cross-Calibrated Multi-Platform (CCMP; www.remss.com/ measurements/ccmp), and Quick Scatterometer (QSCAT Ku-2011 monthly) are produced by Remote Sensing Systems (RSS) and sponsored by the NASA Ocean Vector Winds Science Team. Data are available at www.remss.com/ missions/qscat. Table 1 lists the main parameters of these wind datasets used in this study. The NCEP/NCAR surface wind velocities are chosen to represent coarse resolution; the ERAInterim was chosen to represent medium-high horizontal resolutions comparison; the CCMP was chosen to represent high horizontal resolutions comparison; the QSCAT is satellitederived dataset with high horizontal resolution and the advantage of data-poor area coverage, which is used as a reference dataset in this study.

Surface wind vectors in NCEP/NCAR Reanalysis Products-1 (NNRP-1) data were produced by the National Centers for Environmental prediction (NCEP) in collaboration with the National Centre for Atmospheric Research (NCAR). The data assimilation system uses a 3D-variational analysis scheme, with 28 sigma levels in the vertical and a triangular truncation of 62 waves which corresponds to a horizontal resolution of approximately $2.5^{\circ} \times 2.5^{\circ}$ (Kalnay et al. 1996).

ERA-Interim surface wind vectors are a version of reanalysis data provided by the European Centre for Medium-Range Weather Forecasts (ECMWF). The version has a spatial resolution of $0.7^{\circ} \times 0.7^{\circ}$ and uses $4 \mathrm{D}$-variational analysis on a spectral grid with triangular truncation of 255 waves (corresponds to approximately $80 \mathrm{~km}$ ) and a hybrid vertical coordinate system with 60 levels (Simmons et al. 2007).

The CCMP ocean surface wind analysis velocity product has a high resolution of $0.25^{\circ} \times 0.25^{\circ}$, they use analyses and reanalyses from the ECMWF as prior information, and combine with all the satellite data from Remote Sensing Systems and available conventional data using a variational analysis method (Atlas et al. 2011). 
Table 1 Parameters of the wind datasets used in this study during 2000-2008

\begin{tabular}{|c|c|c|c|}
\hline Name & Included data sources & Temporal resolution & Horizontal resolution \\
\hline NCEP/NCAR & $\begin{array}{l}\text { Numerical weather prediction (NWP) } \\
\text { and observations }\end{array}$ & Monthly & $1.9^{\circ} \times 1.875^{\circ}$ \\
\hline ERA-Interim & NWP and observations & Monthly & $0.7^{\circ} \times 0.7^{\circ}$ \\
\hline CCMP & $\begin{array}{l}\text { QuikSCAT, SSM/I, SSMIS, AMSR-E, } \\
\text { WindSat, ECMWF analyses }\end{array}$ & Monthly & $0.25^{\circ} \times 0.25^{\circ}$ \\
\hline QSCAT & QuikSCAT & Monthly & $0.25^{\circ} \times 0.25^{\circ}$ \\
\hline
\end{tabular}

The QSCAT surface wind vectors are at $25-\mathrm{km}$ resolution over a single $1600-\mathrm{km}$ swath centered on the satellite ground track obtained from the SeaWinds instrument on board QuikSCAT satellite. This microwave instrument measures backscatter radiation in $\mathrm{Ku}$-band $(\sim 14 \mathrm{GHz})$. Rain is a wellknown problem affecting scatterometers, which tends to result in erroneous cross-track vectors and/or unrealistically high speeds. The present work uses the QuikScat Ku-2011 (v4) data, which use 4 satellite microwave radiometers (F13 SSMI, F14 SSMI, F15 SSMI, and TMI) to determine if rain is present at the location of the QuikScat observation (Ricciardulli and Wentz 2011; Ricciardulli and Wentz 2015).

All of the wind vectors are linearly interpolated to a $1^{\circ}$ square grid used for the comparison in this study. The surface wind stress $\tau$ use in this study is calculated based on the bulk aerodynamic formula:

$\tau=\rho C_{D} V \vec{V}$

where $V$ is the wind speed at $10 \mathrm{~m}$ above the sea surface, $\rho_{a}$ is density of air and is set to a constent value of $1.22 \mathrm{~kg} \mathrm{~m}^{-3}$, and $C_{\mathrm{D}}$ is dimensionless drag coefficient, here we use the formula of Garratt (1977) to get the $C_{\mathrm{D}}$,

$C_{D}=7.5 \times 10^{-4}+6.7 \times 10^{-5} \times V$

The WSC is calculated at the center of the wind stress data cells using a centered finite difference scheme following Saunders (1976). We compare the WSC calculated from wind stress by Garratt (1977), Large and Pond (1981), and Foreman and Emeis (2010), which shows no significant difference for the present study.

\subsection{Hydrographic data and climate indices}

The absolute geostrophic current (AGC) data was calculated from both gridded Argo data (http://www.jamstec.go.jp/ ARGO/argo_web/argo/?page_id=83\&lang=en) in the upper $2000 \mathrm{~m}$ during 2001 to 2008 and the climatological hydrographic data of the WOA13 in the upper $5000 \mathrm{~m}$ north of $4^{\circ} \mathrm{N}$ in the North Pacific Ocean using the P-vector method (Chu 1995; Yuan et al. 2014; Zhou et al. 2018). The mean meridional geostrophic transport (MGT) in the North Pacific
Ocean is calculated by integrating the meridional geostrophic velocities from the eastern boundary to the $5^{\circ}$ off the coast in the western boundary in order to avoid the influence of the Mindanao Current (MC) and the Mindanao eddy (ME), which represents the meridional volume transport in interior Ocean.

The El Niño index Niño 3.4 (the SST anomaly averaged over the east-central equatorial Pacific region $5^{\circ}$ S-5 ${ }^{\circ} \mathrm{N}, 170^{\circ}-120^{\circ} \mathrm{W}$ ) is downloaded from (https:// www.esrl.noaa.gov/psd/gcos_wgsp/Timeseries/Data/ nino34.long.anom.data), which is calculated from HadISST1 datasets (Rayner et al. 2003).

\subsection{Sverdrup balance}

Sverdrup theory assumes linear, geostrophic dynamics, and the existence of a depth $H$ in the ocean, beyond which the horizontal and vertical velocities vanish (Sverdrup 1947). The vertically integrated, steady-state momentum, and continuity equations can be written as follows:

$-f V=-P_{x}+\frac{\tau^{x}}{\rho}$,

$f U=-P_{y}+\frac{\tau^{y}}{\rho}$

$U_{x}+V_{y}=0$,

where uppercase symbols $U, V$, and $P$ indicate vertically integrated horizontal velocities and pressure from $-H$ to 0 . Subscripts indicate partial differentiation, $f$ the Coriolis parameter, $\rho$ the water density, and $\tau^{x}, \tau^{y}$ are the zonal and meridional wind stress components, respectively. Taking the curl of the Eqs. (1a) and (1b) and making use of the Eq. (1c), the meridional transport is calculated as follows:

$V=\frac{1}{\beta \rho} \operatorname{curl}(\tau)$

where $\beta=\mathrm{d} f / \mathrm{d} y$ is the meridional gradient of the Coriolis parameter and $\tau$ is the wind stress. The right side of Eq. (2) is called the Sverdrup transport. The vertically integrated meridional transport in Eq. (2) includes the surface Ekman transport 
and the geostrophic transport $\left(V_{\mathrm{g}}\right)$. At each longitude $(x)$, the meridional geostrophic transport along a latitude $y$ is integrated zonally from the eastern boundary $\left(x_{\mathrm{E}}\right)$ of the basin as follows:

$\int_{x_{E}}^{x} \int_{-H}^{0} V_{g} d z d x=\frac{1}{\beta \rho} \int_{x_{E}}^{x} \operatorname{curl} \tau d x+\frac{1}{f \rho} \int_{x_{E}}^{x} \tau^{x} d x$.

Both sides of Eq. (3) vary with $\mathrm{x}$ and $\mathrm{y}$. The left side is called the meridional geostrophic transport (MGT), which is equivalent to the geostrophic streamfunction, and can be calculated from ocean hydrographic data. The right side is the Sverdrup minus the Ekman streamfunction (S-E in abbreviation), which can be computed from surface wind stress.

\subsection{The standard error of the mean}

The standard error of the mean (SEM) at a given confidence level $\alpha$ is calculated based on the Student's $t$ distribution test,

$\operatorname{SEM}_{\alpha}=\frac{\sigma}{\sqrt{N_{\mathrm{d}}}} t_{\alpha / 2}\left(N_{\mathrm{d}}\right)$,

where $\sigma$ is the standard deviation of the time series and $N_{\mathrm{d}}$ is the degrees of freedom estimated based on the autocorrelation $r$ at one time interval of the sampling (Bretherton et al. 1999).

$N_{\mathrm{d}}=\frac{\left(1-r^{2}\right)}{\left(1+r^{2}\right)} N$,

where $N$ is the sample number.

\subsection{The empirical orthogonal function analysis}

To extract dominant patterns and their associated time coefficient functions of the WSC fields, empirical orthogonal function (EOF) was performed on the 12-month running mean time series after the mean values and linear trends were first removed. Given a data set $x(m, t)$ consisting of data from $m$ $(m=1,2, \ldots, M)$ grids and at time $t(t=1,2, \ldots, N)$, if the temporal means of the data from each grid have been removed, these anomalies can be decomposed as (Storch and Zwiers 1999):

$$
x(m, t)=\sum_{i=1}^{C} \alpha_{i}(t) F_{i}(m)
$$

where $\mathrm{F}_{\mathrm{i}}(m)$ is the $i$ th $\mathrm{EOF}$, representing the spatial pattern of the $i$ th mode; $\alpha_{\mathrm{i}}(t)$ is the time coefficient function of the $i$ th mode; and $C=\min (M, N)$. The associated eigenvalues $\left(\lambda_{\mathrm{i}}\right)$ are the variances captured by each EOF, and when sorted by decreasing $\lambda_{\mathrm{i}}$, the leading $\mathrm{n}$ eigenvectors (EOFs) describe more variance than any other $n$ vectors.

\section{Analysis of the WSC fields}

In this section, we compare the annual mean, seasonal, and interannual variability of the sea surface WSC fields over the tropical North Pacific Ocean among NCEP/NCAR, ERAInterim, CCMP, and QSCAT datasets.

\subsection{Annual mean}

The climatological mean sea surface WSC over the tropical North Pacific Ocean from NCEP/NCAR, Interim, CCMP, and QSCAT datasets are displayed in Fig. 1. The spatial patterns of the WSC are basically consistent with each other in the four datasets. All of them show the basin-wide band like structure of positive values with the maximum of $8 \times 10^{-8} \mathrm{~N} / \mathrm{m}^{3}$ south of $15^{\circ} \mathrm{N}$ where the northeast trades build to the north from the Intertropical Convergence Zone (ITCZ) trade wind minimum (Kessler et al. 2003) and negative values with the minimum of $-10 \times 10^{-8} \mathrm{~N} / \mathrm{m}^{3}$ north of $15^{\circ} \mathrm{N}$ in the west-central Pacific. However, there are also some obvious discrepancies between them, for example, the WSCs in the eastern equatorial Pacific Ocean show quite complex structures due to the active air-sea interactions near the cold tongue (Wallace et al. 1989). The small scale structures are missing in the NCEP/NCAR WSC due to its coarse resolution compared with the other three wind products (Fig. 1a). There is a narrow strip of positive WSC just north of the equator between $150^{\circ} \mathrm{W}$ and $100^{\circ} \mathrm{W}$ in the eastern Pacific as revealed by the QSCAT and CCMP (Fig. 1c, d), which is absent in NCEP/NCAR and ERA-Interim. This narrow strip of positive WSC is thought to be a consequence of SST-induced modification of the planetary boundary layer in the southeasterly regime over the eastern equatorial Pacific (Wallace et al. 1989). Kessler et al. (2003) has suggested that this strip of positive WSC is the key to produce the north branch of Equatorial Undercurrent due to its large meridional derivatives and large contribution to the zonal integral. The present study will discuss about its contribution to the meridional transport in the following sections.

The dipole WSC structure near the Hawaii land mass in response to orographic effects of the islands is quite strong in all wind products (Xie et al. 2001). High resolution clearly has a more consistent structure of this dipole with the QSCAT. Although the NCEP/NCAR has a coarse resolution, its amplitude is much larger than the other winds, and it has an unrealistic WSC dipole centering along the zero WSC line around $165^{\circ}$ E (Fig. 1a). Previous studies have suggested the tropical bias in the NCEP/NCAR wind stresses, which tend to be systematically low when compared with observations by ships and scatterometer (Stricherz et al. 1997; Milliff et al. 1999; Smith et al. 1999). However, the WSC calculated from the present version of NCEP/NCAR products during 2000-2008 shows systematically high amplitude compared with other 
Fig. 1 Annual mean wind stress curl (in unit of $10^{-8} \mathrm{~N} / \mathrm{m}^{3}$ ) over tropical North Pacific Ocean from the NCEP/NCAR (a), ERAInterim (b), CCMP(c), and QSCAT (d). Contour interval is $2 \times 10^{-8} \mathrm{~N} / \mathrm{m}^{3}$. The thick black lines represent the zero contours
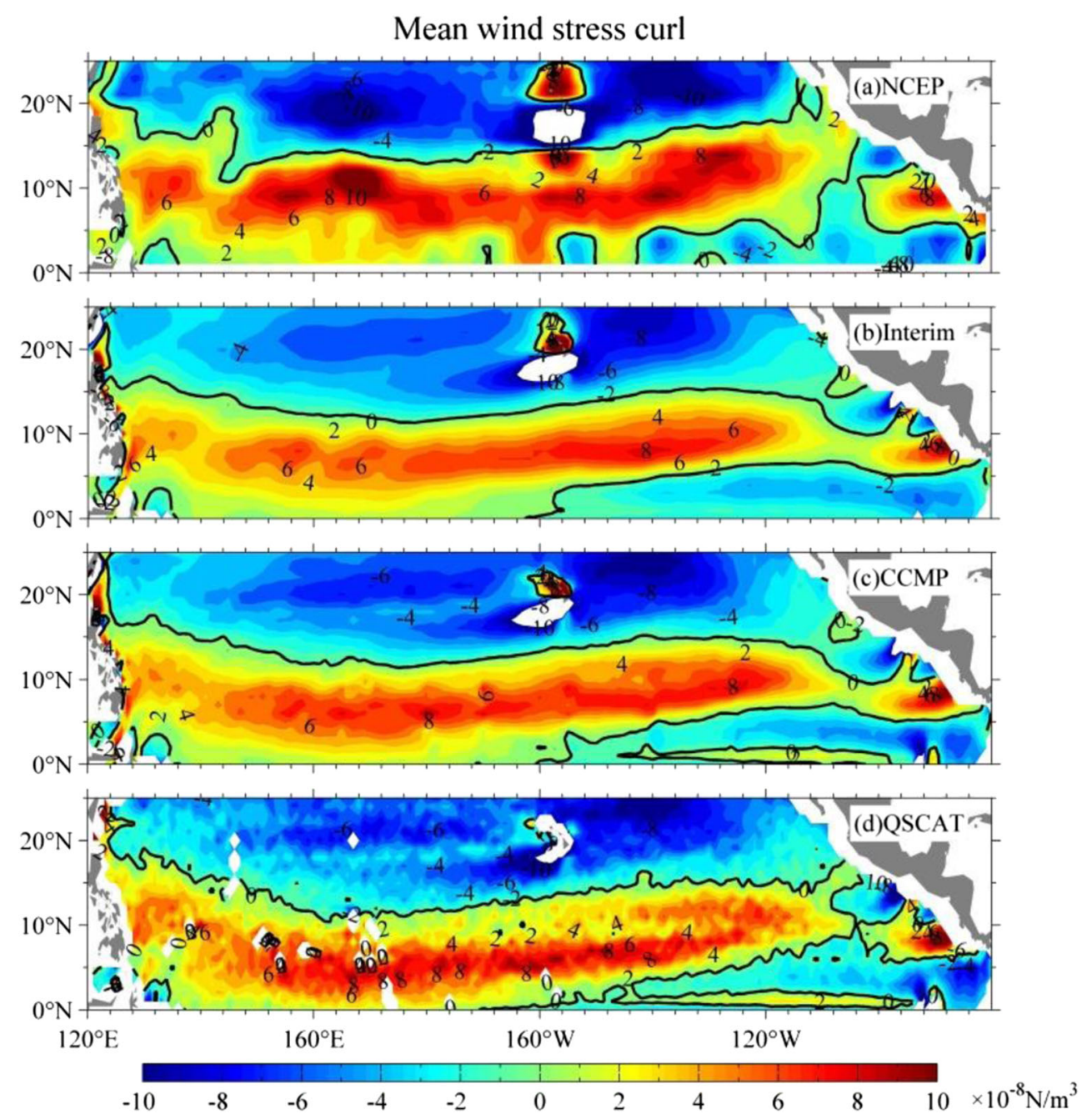

three wind products in the tropical Pacific Ocean. The zero line of WSC between tropical and subtropical gyre locates around $12-15^{\circ} \mathrm{N}$ with a little northward inclination in the western boundary, which is consistent with the mean surface bifurcation latitude of North Equatorial Current observed from altimetry data (Wang and $\mathrm{Hu}$ 2006; Qiu and Chen 2010). Large differences are identified near the western and eastern boundary region among the three reanalysis/ analysis wind products, which may be caused by different resolutions.

\subsection{Seasonal variability}

The seasonal distribution of the WSC climatology averaged during March-May (boreal spring), June-August (boreal summer), September-November (boreal autumn), and December, January, and February (boreal winter) are shown in Fig. 2. The positive curl south of $15^{\circ} \mathrm{N}$ is strongest in winter in both amplitude and spatial extent, which is related to the southward shifting of the ITCZ in winter. The pattern in spring is similar to that in winter except that the amplitude is a little smaller. In summer and autumn, the positive WSC shifts northward with its amplitude and meridional width being reduced. The northern boundary of this positive WSC in the western Pacific Ocean clearly shows a northwestward expansion, which is related to the frequent passage of tropical cyclones, prevalent from June to November. Of the four products, the seasonal variations of the CCMP curl are closest to QSCAT in pattern and intensity due to its high resolution and assimilation of the QuikScat data.

\subsection{Interannual variability}

The interannual signals of the WSC are studied using monthly anomaly data by subtracting the corresponding monthly climatology from the monthly mean fields and removing the linear trend, and then filtered in time with a 12-month running mean filter in order to focus on the interannual time scale (Emery and Thomson 2001). The EOF decomposition is then performed to these four interannual WSC fields in order to extract the dominant EOF patterns and their corresponding 
Fig. 2 Seasonal sea surface wind stress curl (in unit of $10^{-8} \mathrm{~N} / \mathrm{m}^{3}$ ) over North Pacific Ocean from the NCEP/NCAR, Interim, CCMP, and QSCAT datasets. Contour interval is $2 \times 10^{-8} \mathrm{~N} / \mathrm{m}^{3}$. The thick black lines represent the zero contours
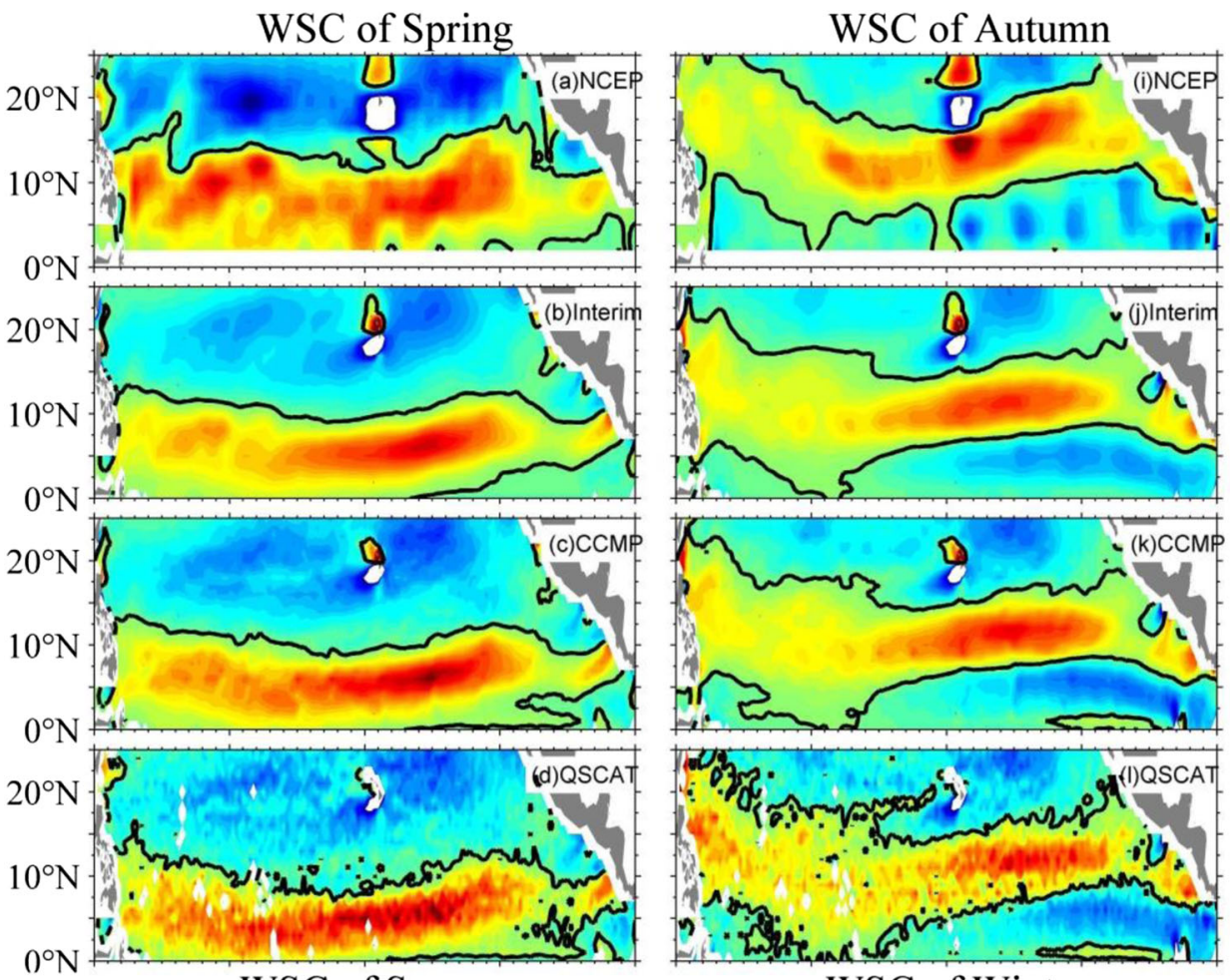

WSC of Summer
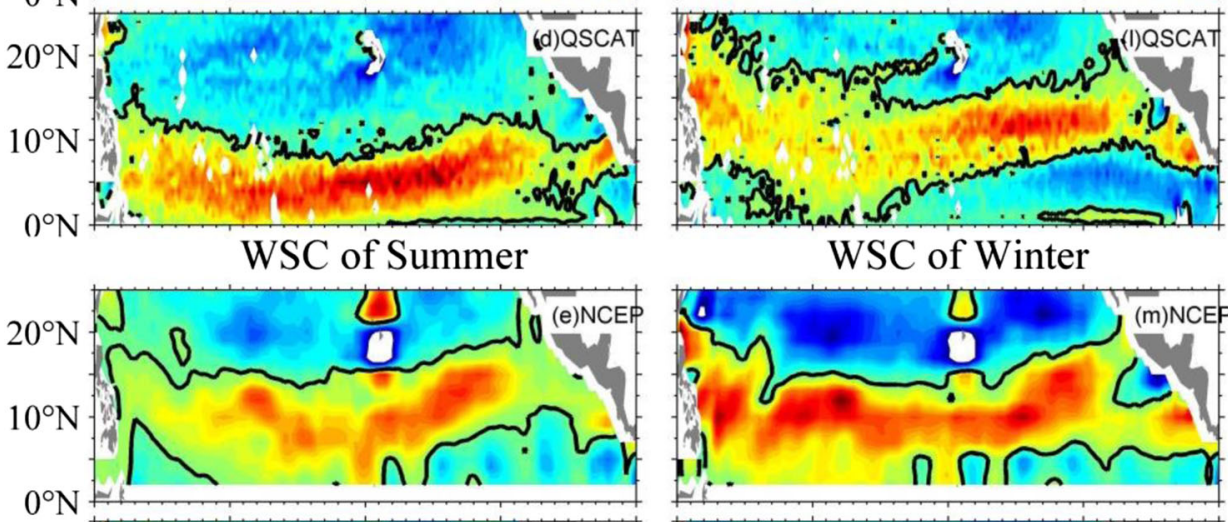

WSC of Winter
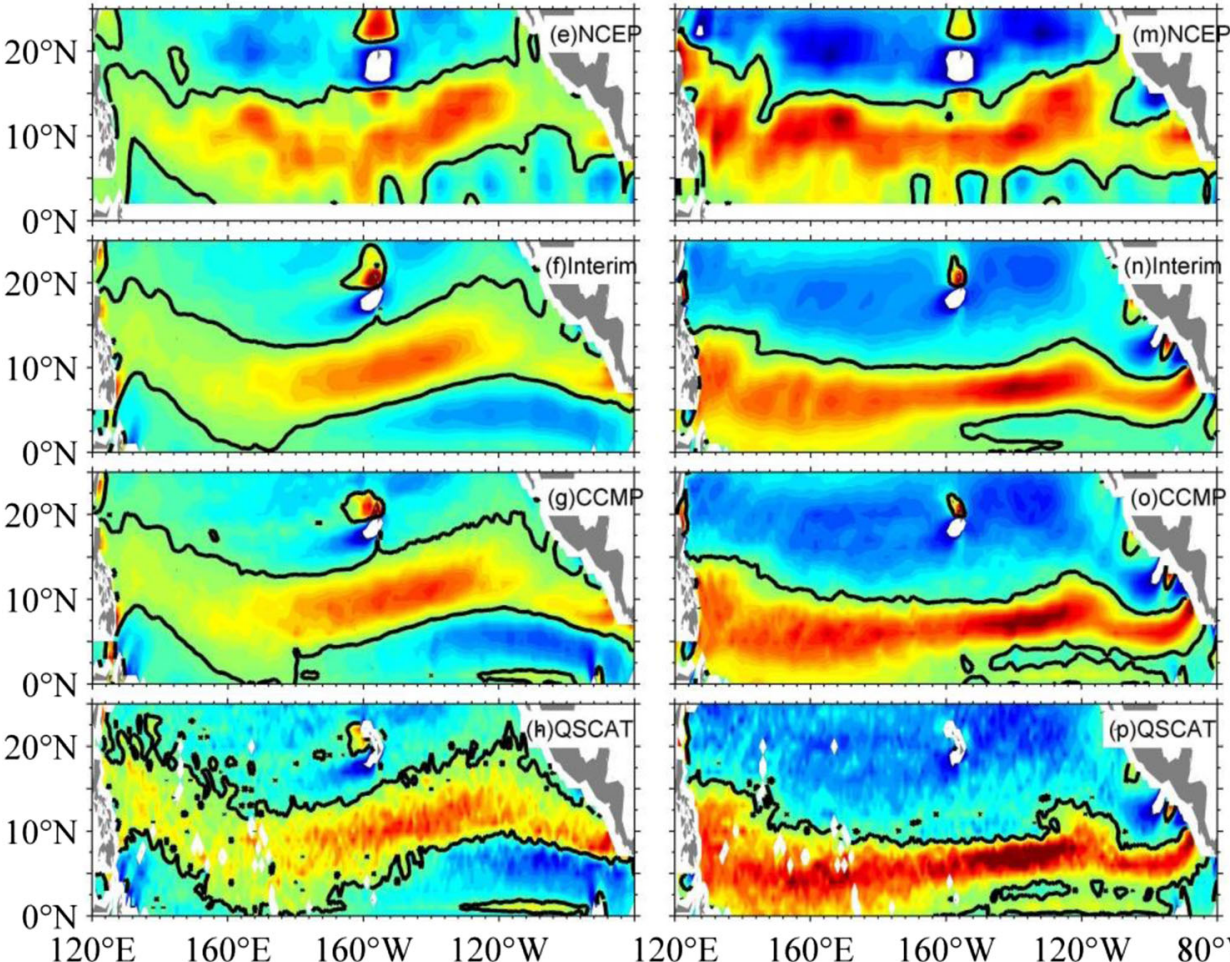

$120^{\circ} \mathrm{E} \quad 160^{\circ} \mathrm{E} \quad 160^{\circ} \mathrm{W} \quad 120^{\circ} \mathrm{W} \quad 120^{\circ} \mathrm{E} \quad 160^{\circ} \mathrm{E} \quad 160^{\circ} \mathrm{W} \quad 120^{\circ} \mathrm{W} \quad 80^{\circ} \mathrm{W}$

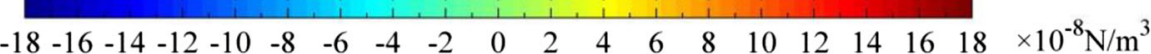

time coefficient functions (Storch and Zwiers 1999). The first EOF mode of the WSC (WSC-1) explains about 39\%, 32\%, $29 \%$, and $19 \%$ of the total variances for NCEP/NCAR, ERAInterim, CCMP, and QSCAT, respectively. The spatial patterns from ERA-Interim, CCMP, and QSCAT datasets are quite similar except the NCEP/NCAR, which misses the narrow band of negative WSC south of $5^{\circ} \mathrm{N}$ east of $160^{\circ} \mathrm{W}$ due to its coarse resolution (Fig. $3 \mathrm{a}-\mathrm{d}$ ). Moreover, there is an 


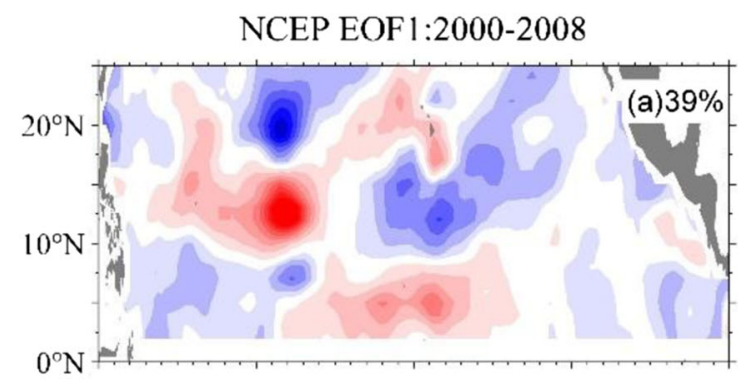

Interim EOF 1:2000-2008

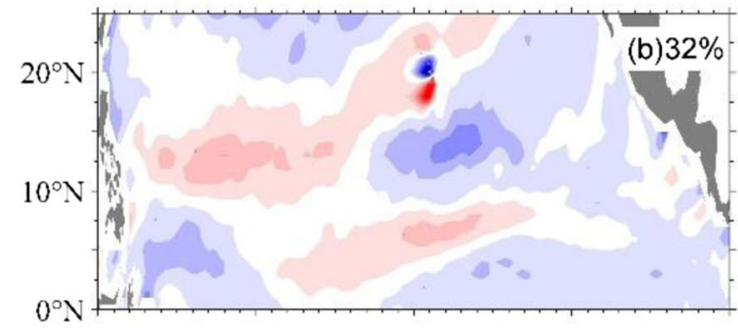

CCMP EOF 1:2000-2008

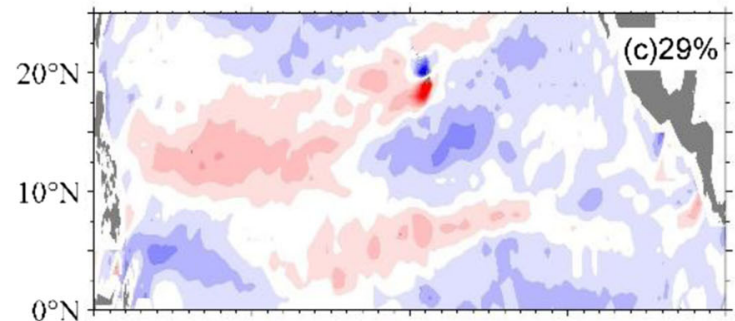

QSCAT EOF1:2000-2008

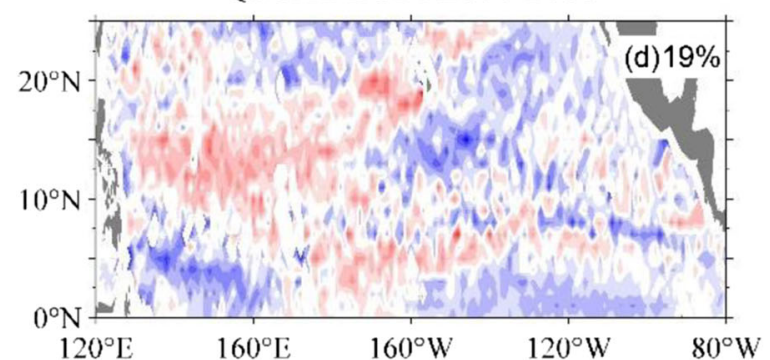

$\mathrm{PC} 1$ \& Nino3.4
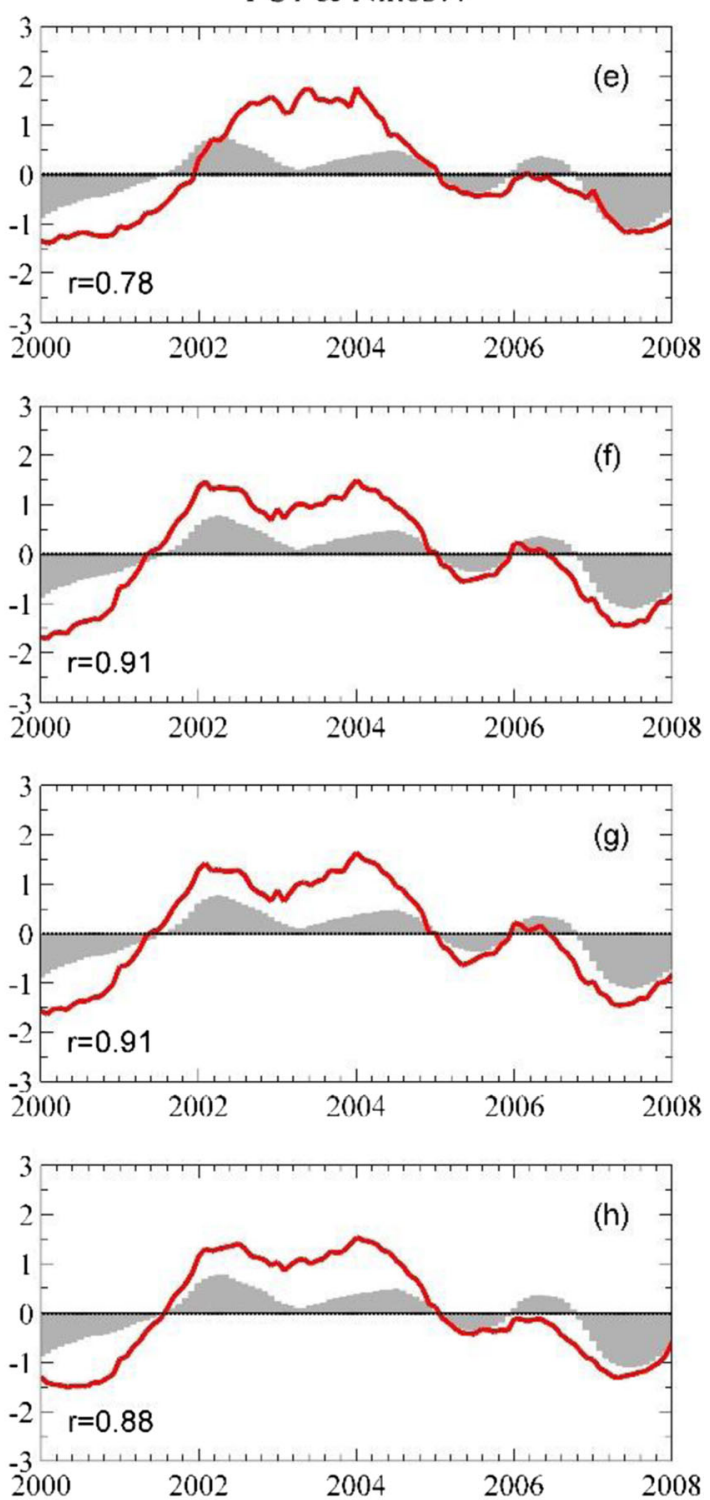

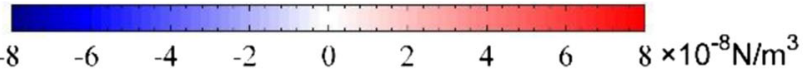

Fig. 3 The first EOFs of wind stress curl (a-d) and the corresponding principle component time coefficients (e-h). The shaded bars are the 12-month running mean Niño3.4 index, and $r$ is the correlation coefficient between PC 1 and Niño3.4 index. Contour interval is $1 \times 10^{-8} \mathrm{~N} / \mathrm{m}^{3}$

unrealistic dipole structure between 10 and $20^{\circ} \mathrm{N}$ along $165^{\circ}$ $\mathrm{E}$ in the NCEP/NCAR (Fig. 3a). All wind products show a band of positive WSC tilting northward near the equator from $160^{\circ} \mathrm{E}$ to $120^{\circ} \mathrm{W}$, which is consistent with the westerly wind anomalies associated with the development of El Niño (Clarke et al. 2007).

The time series of the first principal component (PC1) from the four wind products show very high simultaneous correlations with the Niño3.4 index with the lowest value of 0.78 for NCEP/NCAR and the highest value of 0.91 for the Interim (Fig. 3e-h). The high correlations suggest that the major interannual modes of the surface WSC are dominated by ENSO.
Since ENSO behavior is highly sensitive to changes in the wind forcing (Neelin 1990; Kirtman 1997; An and Wang 2000; Cassou and Perigaud 2000), it is very important to investigate the differences of the interannual variations in the WSC in tropical North Pacific Ocean among the four wind products.

Figure 4 shows the differences of interannual WSC anomalies between reanalysis/analysis WSC and QSCAT averaged in the band of $7^{\circ}-9^{\circ} \mathrm{N}$. The reason for choosing this latitudinal band will be explained in the following sections. Although the large-scale features of these reanalysis/analysis wind products bear some resemblance in their deviation from the QSCAT, 

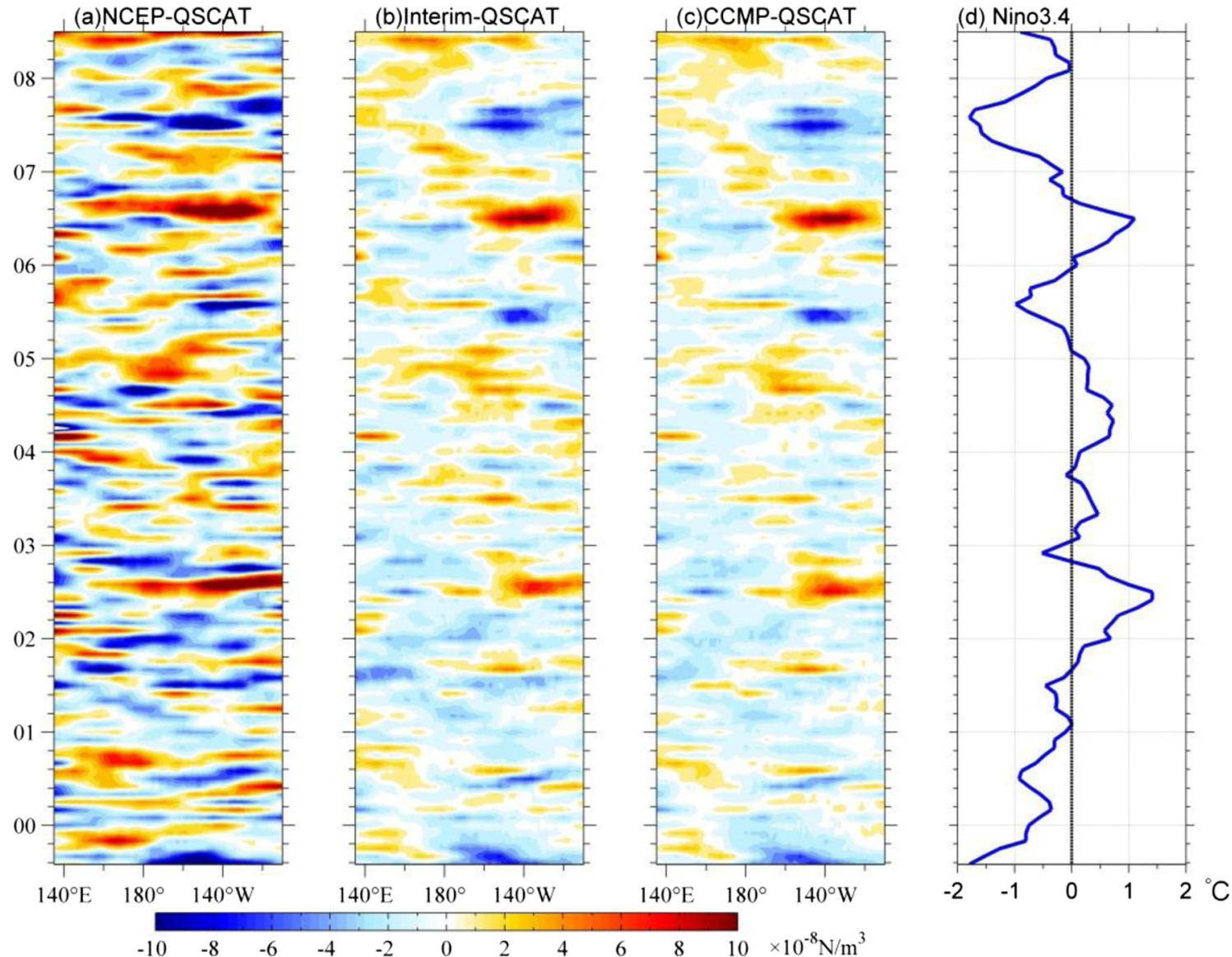

Fig. 4 The Hovmöller diagrams of the differences between the interannual wind stress curl anomalies of NCEP/NCAR (a), ERA-Interim (b), and CCMP (c) and the QuikScat, respectively. The unit is $1 \times 10^{-8} \mathrm{~N} / \mathrm{m}^{3}$. The Niño3.4 index, and the unit is ${ }^{\circ} \mathrm{C}(\mathbf{d})$

the differences among them are obvious. Generally speaking, the NCEP/NCAR clearly shows the largest differences with the QSCAT (Fig. 3a), and the maximum difference exceeds $10 \times 10^{-8} \mathrm{~N} / \mathrm{m}^{3}$ in some years, which is the same amplitude as the annual mean WSC. The ERA-Interim and CCMP show much smaller differences from the QSCAT compared with that of NCEP/NCAR in most years (Fig. 3b, c). Moreover, there are much better agreements among the four datasets during normal years than during cold/warm years. The differences of interannual WSC anomalies between reanalysis/ analysis WSC and QSCAT tend to be positive with the maximum amplitude of $10 \times 10^{-8} \mathrm{~N} / \mathrm{m}^{3}$ in the central-eastern Pacific during the 2006 and 2002 El Niño events, and negative with the maximum amplitude of $8 \times 10^{-8} \mathrm{~N} / \mathrm{m}^{3}$ between $180^{\circ} \mathrm{W}$ and $140^{\circ} \mathrm{W}$ during the 2000, 2005, and $2007 \mathrm{La}$ Niña events. In tropical Pacific Ocean, changes in WSC will alter the SST and heat distribution through Rossby waves, the large differences between the reanalysis/analysis WSC and the QSCAT during ENSO events may influence the ENSO strength or structure in the forced models.

\section{The Sverdrup transport in tropical North Pacific Ocean}

The Sverdrup theory provides an efficient way to estimate the meridional transport of the wind-driven ocean circulation by integrating the WSC. This provides a simple way to assess the large scale differences in these four WSC fields by comparing the predicted Sverdrup transport distributions with the observed MGT calculated from long-term mean hydrographic data.

\subsection{Mean field over the tropical North Pacific Ocean}

According to Eq.(3), the climatological mean MGT calculated from WOA13 and Argo data, the mean S-E transport evaluated from the four wind products are shown in Fig.5a, $\mathrm{f}$ and Figs. $5 \mathrm{~b}-\mathrm{e}$ respectively. The comparison between the MGT and S-E is under the assumption that the ocean is in steady state. Given the fact that the low frequency wave adjustment time is less than 5 years south of $25^{\circ} \mathrm{N}$ in the North Pacific Ocean (Chelton et al. 2001), the 9-years long time period of the wind products is long enough for the ocean to reach a steady state. 
Fig. 5 Meridional geostrophic transport (MGT) calculated from the WOA13 (a) and Argo profiling float data (f) in the tropical North Pacific Ocean; The mean Sverdrup minus Ekman (S-E) transport based on the NCEP/NCAR, ERA-Interim, CCMP, and QSCAT wind products $(\mathbf{b}-\mathbf{e})$; Difference between MGT and the S-E transport $(\mathbf{g}-\mathbf{j})$. Unit is Sv. Negative values are shaded
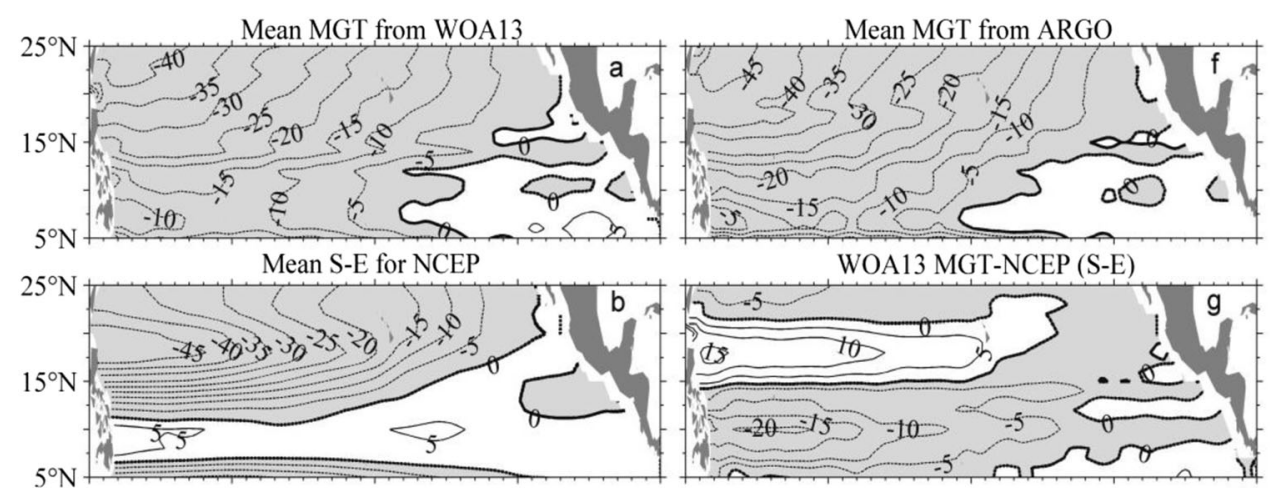

WOA13 MGT-Interim(S-E)
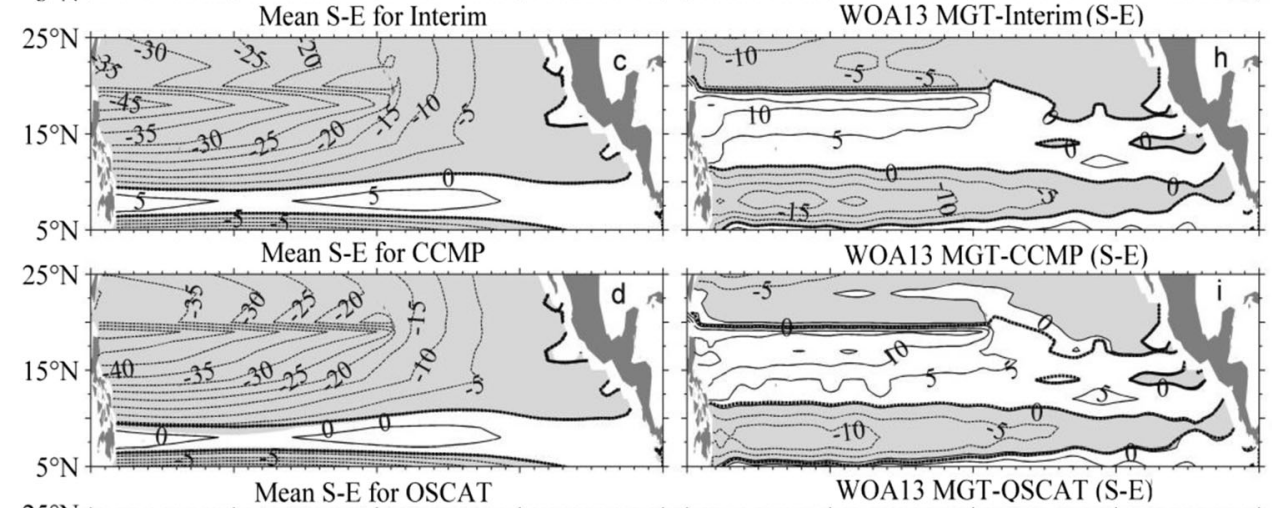

WOA13 MGT-QSCAT (S-E)
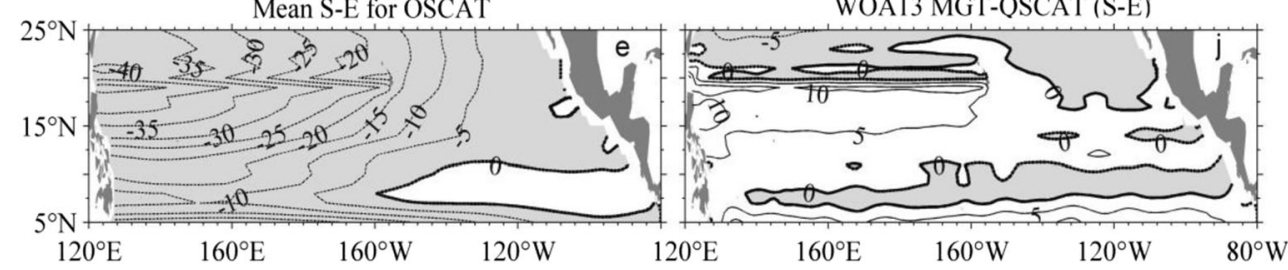

The MGT is integrated from the $1500 \mathrm{~m}$ depth to the sea surface and from the eastern boundary of the North Pacific Ocean to the grids $5^{\circ}$ away from the western boundary, and the S-E transport is also zonally integrated the same way as that for the MGT. The mean MGT from WOA13 is mostly southward in the tropical North Pacific Ocean, which mainly represents the interior subtropical-tropical gyre circulation (Fig. 5a), with the maximum transport of $40 \mathrm{~Sv}(1 \mathrm{~Sv}=$ $10^{6} \mathrm{~m}^{3} \mathrm{~s}^{-1}$ ) locating east of Taiwan Island. This is consistent with the mean MGT calculated from 57-year long pentadal hydrographic data by Zhou et al. (2018). The MGT calculated from 8-year long Argo profiling float data shows basically consistent patterns only the maximum transport exceeds $45 \mathrm{~Sv}$. The consistency between the MGT from WOA13 and Argo data suggests that the tropical Pacific Ocean is in a steady state for the 2000-2008 period's mean.

In comparison, the S-E transports show quite similar spatial pattern in the four wind products in the subtropical gyre, which are qualitatively consistent with that of the MGT in the subtropical gyre and near the eastern boundary in the North Pacific Ocean (Fig. 5b-e), suggesting the dominance of wind-driven circulation in these areas. However, the maximum southward S-E transports in all wind products are not co-located with those of the MGT, with the S-E maximum shifted a little southward toward the Luzon Strait. Another obvious difference is that all of the S-E transports are northward in the band of $7^{\circ}-9^{\circ} \mathrm{N}$ except that of the QSCAT, which produces more realistic southward transport as shown in the MGT.

The amplitudes of the differences between the MGT and the S-E transports in the four datasets are shown in Figs. $5 \mathrm{~g}-\mathrm{j}$. The maximum positive difference $(10 \sim 15 \mathrm{~Sv})$ roughly locates east of the Luzon Island $\left(15^{\circ}-20^{\circ} \mathrm{N}\right)$, where the maximum S$\mathrm{E}$ transport locates. This large positive value indicates the large differences of the zero line of WSC in tropicalsubtropical gyre in the western Pacific Ocean, which is consistent with the distribution of WSC shown in Fig. 1 and previous studies (Yuan et al. 2014; Zhou et al. 2018). There is also a maximum negative difference $(-15 \sim 20 \mathrm{~Sv})$ in the three reanalysis/analysis wind products east of the Mindanao Island (Fig. 5g-i), which is absent in the QSCAT (Fig. 5j). Generally, the differences in Fig. 5j are the smallest, suggesting that the QSCAT wind predicts a more realistic meridional transport compared with the other three reanalysis/analysis wind products in the tropical Pacific Ocean. 
In order to investigate the significance of these differences between the MGT and S-E transport, Fig. 6 shows the standard error of the mean (SEM) S-E transports for the four wind products. The large SEM values are located roughly near the North Equatorial Current (NEC) bifurcation region and east of the Mindanao Island. The former region is associated with the large variation of the zero line of the WSC in different wind products, and the latter region may be related to the cyclonic recirculation area composed by the NEC, the MC, and the NECC. Generally, none of the SEMs exceed 3.5 Sv in all of the wind products, suggesting the significance of the differences between the S-E and MGT ( $>5 \mathrm{~Sv}$ ) identified in Fig. $5 \mathrm{~g}-\mathrm{j}$.

\subsection{Along $24^{\circ} \mathrm{N}$ and $8^{\circ} \mathrm{N}$}

In order to quantify the differences of S-E transport among the four datasets, Fig. 7 shows the mean zonally integrated S-E transport along $24^{\circ} \mathrm{N}$ (Fig. 7a) and $8^{\circ} \mathrm{N}$ (Fig. 7b) from those four datasets in comparison with the mean zonally integrated MGT estimated from WOA13 and ARGO hydrographic data.

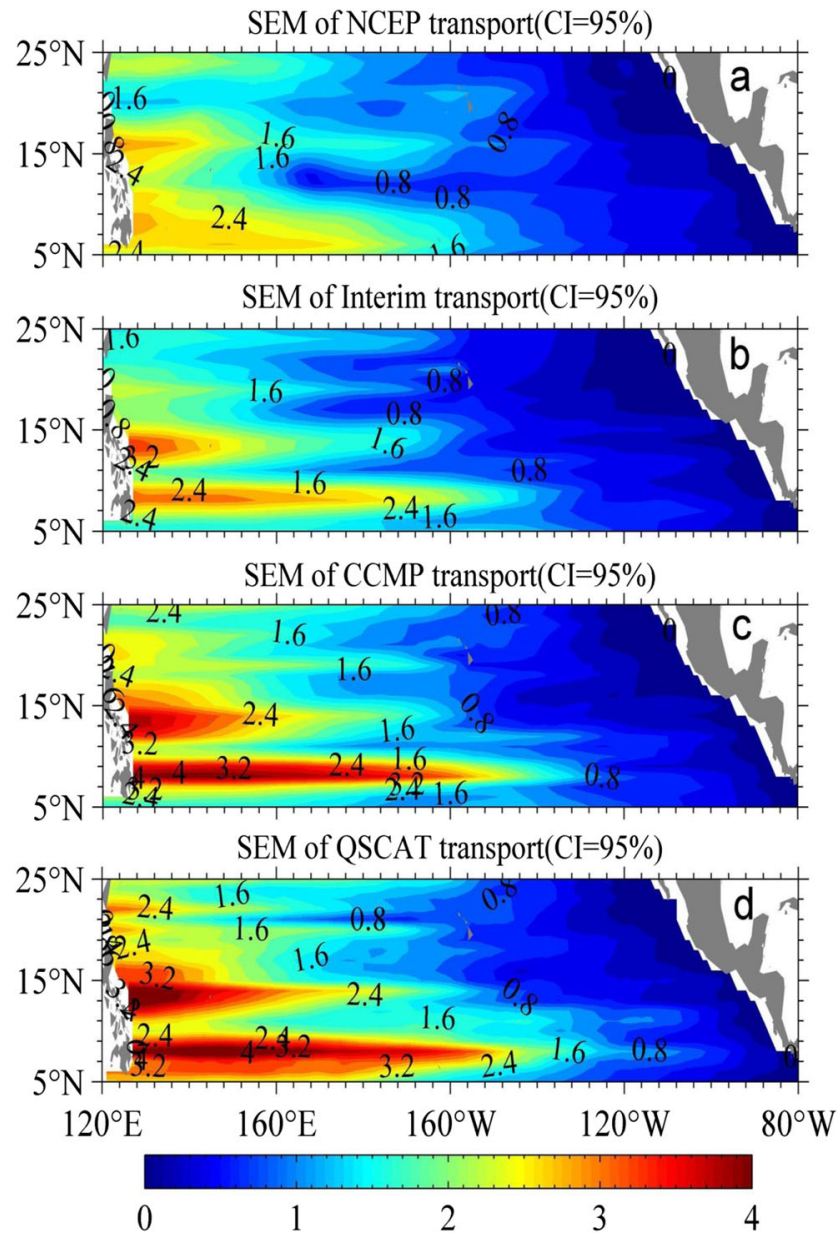

Fig. 6 Standard error of the mean S-E transport of the NCEP/NCAR (a), ERA-Interim (b), CCMP (c), and QSCAT (d) wind stress curl. Unit is Sv. The confidence level is at 95\% of the Student's $t$ test. Intervals for the contours are $0.2 \mathrm{~Sv}$
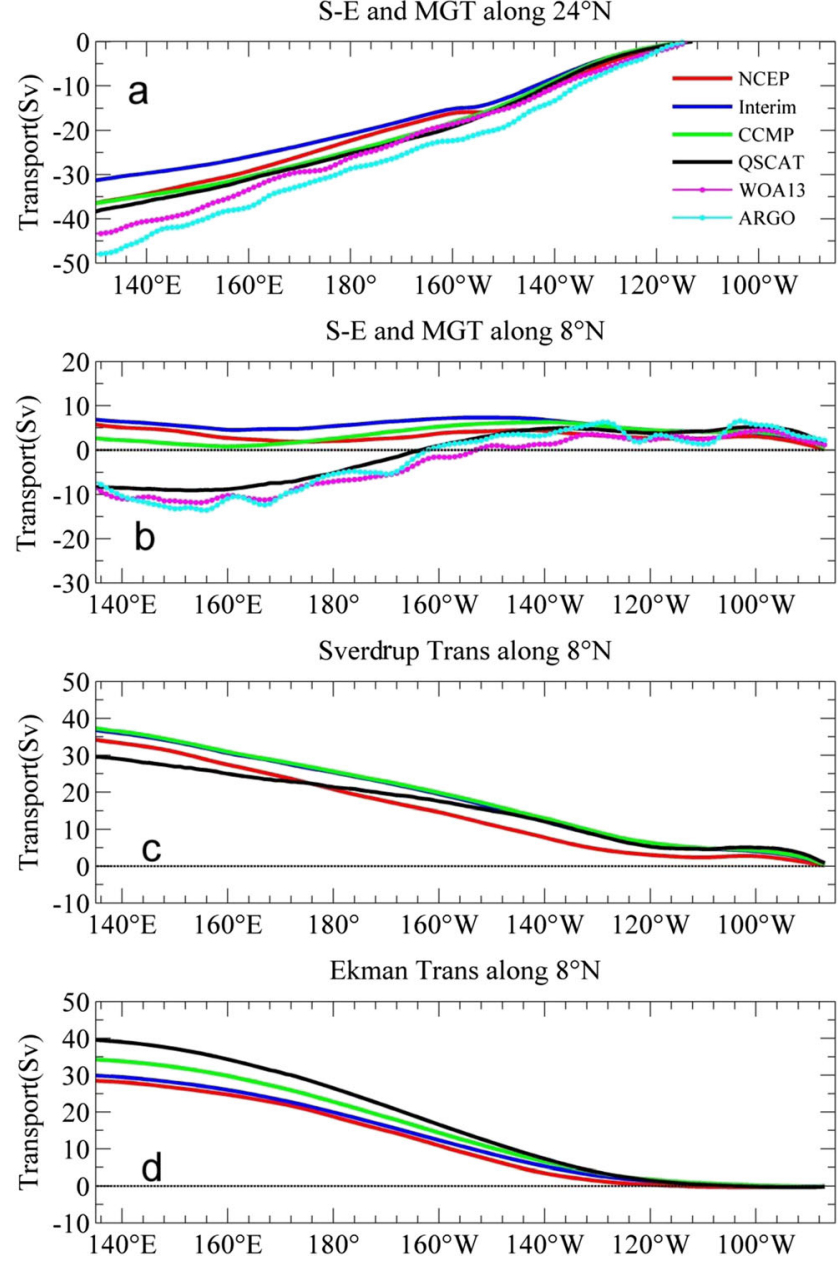

Fig. 7 Longitudinal distribution of the mean S-E and MGT along $24^{\circ} \mathrm{N}$ (a) and $8^{\circ} \mathrm{N}\left(\right.$ b), the Sverdrup (c) and Ekman (d) transport at $8^{\circ} \mathrm{N}$ in the tropical North Pacific Ocean. Unit is Sv

The two latitudes are chosen because the $24^{\circ} \mathrm{N}$ has been suggested to follow the Sverdrup dynamics well (Hautala et al. 1994; Jiang et al. 2006; Aoki and Kutsuwada 2008; Wunsch 2011; Gray and Riser 2014), and the $8^{\circ} \mathrm{N}$ has been suggested to be out of phase with the Sverdrup dynamics (Yuan et al. 2014; Thomas et al. 2014; Zhou et al. 2018). Meanwhile, the $8^{\circ} \mathrm{N}$ is the central latitude where the mean S-E transports show significant discrepancies between the reanalysis/analysis winds and the QSCAT (recall Fig. 5).

At $24^{\circ} \mathrm{N}$, the S-E transports and the MGT show consistent monotone increase of southward transport ranging from 30 to $42 \mathrm{~Sv}$, which is consistent with historical calculation (Godfrey 1989; Trenberth et al. 1990; Qiu and Joyce 1992; Hautala et al. 1994). But the amplitudes of S-E transport are about 7-15 Sv smaller than that of the MGT with the Interim being the smallest and the QSCAT being the largest. At this latitude, the S-E transports calculated from high-resolution CCMP and QSCAT wind products seem to have more realistic value suggesting the importance of the horizontal resolution of wind products in calculating the meridional transport in this region. 
At $8^{\circ} \mathrm{N}$, all of the $\mathrm{S}-\mathrm{E}$ transports show a net northward transport across the Pacific Ocean except the QSCAT wind, which shows consistent increasing southward transport from $160^{\circ} \mathrm{W}$ to the western boundary region. These results are consistent with that in Fig. 5a, e. Although the CCMP assimilates the QSCAT and has the same high resolution as the QSCAT, it fails to produce more realistic ocean circulation just as the coarse resolution wind products do here. Both the Sverdrup and Ekman transports in all wind products show consistent northward transport at $8^{\circ} \mathrm{N}$ (Fig. 7c, d), but the amplitudes differ from each other significantly. The reanalysis/analysis winds seem to overestimate the Sverdrup transport and underestimate the Ekman transport in this region.

In order to investigate the causes of these differences, the zonal profiles of WSC and zonal wind stress averaged between $7^{\circ}$ and $9^{\circ} \mathrm{N}$ for NCEP/NCAR, ERA-Interim, CCMP, and QSCAT across the tropical North Pacific Ocean are shown in Fig. 8. We can see that the QSCAT has smaller WSC and larger zonal wind stress compared with other three wind products especially in the central Pacific. This supports the result of small Sverdrup transport and large Ekman transport calculated from QSCAT shown in Fig. 7. The failure of highresolution CCMP wind product in producing realistic ocean circulation in the tropical Pacific Ocean suggesting the deficiency of the model physics used in these reanalysis/analysis wind products in this region.

\section{Discussions and summary}

Previous studies suggest that Sverdrup and Ekman transport undergo large seasonal variation in the topical North Pacific (Trenberth et al. 1990; Wu and Kinter III 2010). In order to investigate the influence of different seasonal variations of wind stress and WSC on the Sverdrup and Ekman transport among the four wind products, the seasonal distribution of wind stress and WSC is presented in Fig. 9. The most significant differences between reanalysis/analysis and QSCAT wind products occur in winter and summer for both WSC and zonal wind stress. In winter, the QSCAT has much smaller positive WSC and much larger westward zonal wind stress compared with those in other three wind products, which will result in small northward Sverdrup transport and large northward Ekman transport, hence a southward S-E transport. However, in summer, the QSCAT has much larger negative WSC and much larger eastward zonal wind stress compared with those in other three wind products, which will result in
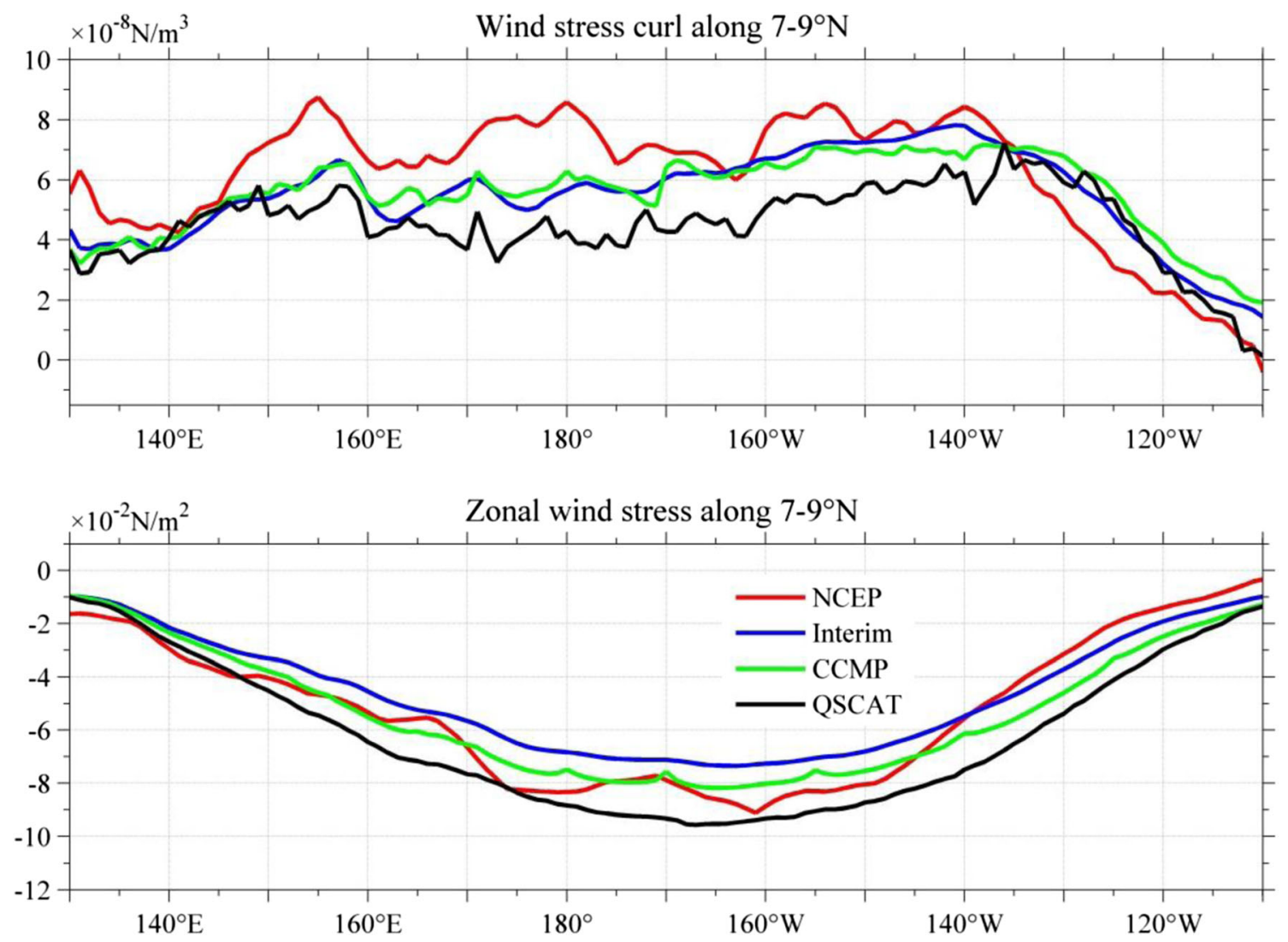

Fig. 8 The zonal profiles of wind stress curl (a) and zonal wind stress (b) averaged between 7 and $9^{\circ} \mathrm{N}$ for NCEP/NCAR (red), ERA-Interim (blue), CCMP (mega), and QSCAT (green) across the tropical North Pacific Ocean. Unit is $1 \times 10^{-8} \mathrm{~N} / \mathrm{m}^{3}$ 

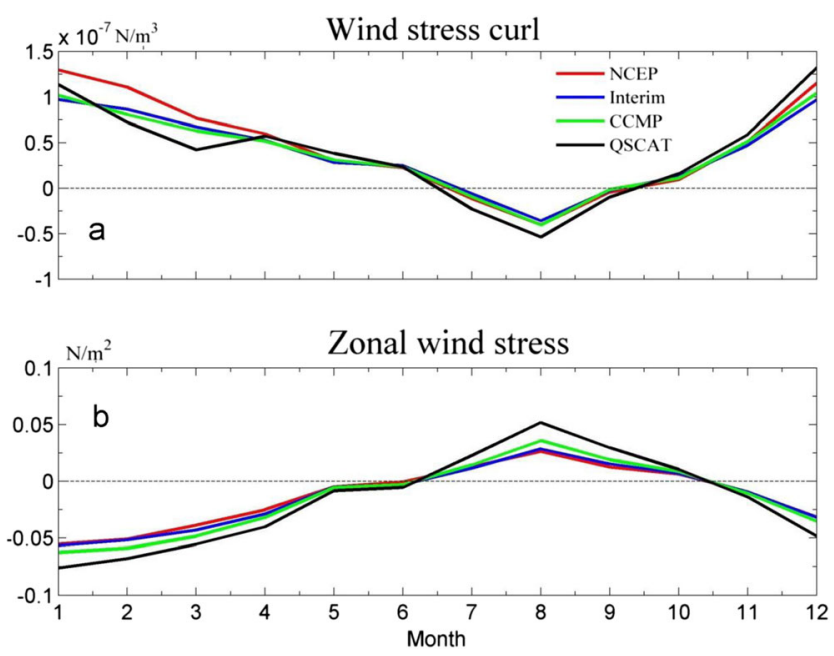

Fig. 9 Seasonal variation of the zonally integrated wind stress curl (a) and zonal wind stress (b) averaged between 130 and $140^{\circ} \mathrm{E}$ at $8^{\circ} \mathrm{N}$ calculated from the NCEP/NCAR (red), Interim (blue), CCMP (mega), and QSCAT (green) datasets. Unit is N/m $\mathrm{m}^{3}$ for wind stress curl and N/m for wind stress

large southward Sverdrup transport and large southward Ekman transport. Because the Ekman transport is much larger than the Sverdrup transport in tropical Pacific Ocean, the S-E transport in summer is northward. So the wind stress and WSC in winter in QSCAT contribute to the mean field of southward S-E transport in this region.

The region between $7^{\circ}$ and $9^{\circ} \mathrm{N}$ in Pacific Ocean is also the boundary between the NEC and NECC, where active activities of meso-scale eddies and fronts associated with velocity shear of the two currents and the meanders of the NECC locate. Many studies have shown that ocean fronts and eddies can influence the wind stress and WSC structures (Kelly et al. 2001; Cornillon and Park 2001; Chelton et al. 2004; Xie 2004). Numerical weather prediction models tend to underestimate the small scale structures in WSC and divergence (Milliff and Morzel 2001; Milliff et al. 2004), overestimate the latent and sensible hear fluxes in these frontal or eddy region (Rouault et al. 2003), which results in unrealistic wind stress and wind stress curl over oceanic fronts and meso-scale eddies.

The ME and the Mindanao Dome also locate in the band of $7^{\circ}-9^{\circ} \mathrm{N}$ in western Pacific, where the thermocline is very shallow due to strong upwelling associated with the ME and Ekman pumping induced by local wind forcing (Masumoto and Yamagata 1991; Tozuka et al. 2002; Zhou et al. 2010). Kutsuwada et al. (2018) suggest that simulated ocean currents and oceanic internal structure using NCEP winds exhibit significant differences from that of QSCAT and observations along $10^{\circ} \mathrm{N}$ in the western tropical Pacific Ocean by comparing outputs from ocean general circulation models driven by NCEP and QSCAT wind datasets. They argue that the shallower thermocline depth is more sensitive to unrealistically strong wind stress curl, which results in substantial bias in the oceanic field in the ocean interior. Further analysis about the dynamics of this discrepancy is of course very valuable, which will be investigated in our future study.

This paper investigates the sensitivity of the Sverdrup transport to the NCEP/NCAR, ERA-Interim, CCMP, and QSCAT wind products over the tropical North Pacific Ocean during the period of 2000-2008. The major results are summarized as follows: All of the S-E transports in the reanalysis/analysis winds are northward in the band of $7^{\circ}$ $9^{\circ} \mathrm{N}$ except the QSCAT wind, which produces more realistic southward transport as shown in the MGTs calculated from WOA13 and Argo data. At $24^{\circ} \mathrm{N}$, high-resolution wind products can better estimate the meridional transport in this region. At $8^{\circ} \mathrm{N}$, although the CCMP has the same high resolution as the QSCAT, it fails to produce more realistic ocean circulation just as the coarse resolution wind products do there. This suggests the deficiency of the model physics used in these reanalysis/analysis wind products in this region, which tend to overestimate the latent and sensible hear fluxes in ocean frontal or eddy region, results in unrealistic wind stress and wind stress curl over oceanic fronts and meso-scale eddies.

Given the fact that most climate models are coarse resolution and basically follow the Sverdrup dynamics, the accurate and detailed simulation of the general ocean circulation will rely on better wind estimates. Although winds are internally generated in ocean-atmosphere coupled models, accurate wind forcing is very important for model initialization especially when these models are used for prediction. Errors in wind stress forcing affect not only the interior ocean but the western boundary as well, since systematic errors in the wind field accumulate toward the west. The failure of the reanalysis/ analysis wind products in depicting the front-induced positive strip of WSC in the equatorial eastern Pacific and the southward S-E transport in the tropical Pacific Ocean between $7^{\circ}$ and $9^{\circ} \mathrm{N}$ could lead to considerable uncertainty in model studies of higher-order processes such as meridional heat transport, which depend on accurate simulation of both interior and western boundary currents. Further studies are highly needed to investigate the dynamical mechanisms in these discrepancies in this region.

Acknowledgements We thank two anonymous reviewers for their valuable comments.

Funding information The work is supported by the grants NSFC (41876009), QMSNL (2016ASKJ12), and NSFC (41421005, 41720104008).

Open Access This article is distributed under the terms of the Creative Commons Attribution 4.0 International License (http:// creativecommons.org/licenses/by/4.0/), which permits unrestricted use, distribution, and reproduction in any medium, provided you give appropriate credit to the original author(s) and the source, provide a link to the Creative Commons license, and indicate if changes were made. 


\section{References}

An S-I, Wang B (2000) Interdecadal change of the structure of the ENSO mode and its impact on the ENSO frequency. J Clim 13:2044-2055

Aoki K, Kutsuwada K (2008) Verification of the wind-driven transport in the North Pacific subtropical gyre using gridded wind-stress products. J Oceanogr 64:49-60. https://doi.org/10. 1007/s10872-008-0004-6

Atlas R, Hoffman RN, Ardizzone J, Leidner SM, Jusem JC, Smith DK, Gombos D (2011) A cross-calibrated, multiplatform ocean surface wind velocity product for meteorological and oceanographic applications. Bull Am Meteorol Soc 92:157-174. https://doi.org/10. 1175/2010BAMS2946.1

Bentamy A, Queffeulou P, Quilfen Y, Katsaros K (1999) Ocean surface wind fields estimated from satellite active and passive microwave instruments. IEEE Trans Geosci Remote Sens 37:2469-2486

Bourassa MA, Legler DM, O'Brien JJ, Smith SR (2003) SeaWinds validation with research vessels. J Geophys Res 108:3019. https://doi. org/10.1029/2001JC001028

Bretherton C, Widmann M, Dymnikov V, Wallace J, Bladé I (1999) The effective number of spatial degrees of freedom of a time-varying field. J Clim 12:1990-2009

Bromwich DH, Fogt RL (2004) Strong trends in the skill of the ERA-40 and NCEP-NCAR reanalyses in the high and midlatitudes of the southern hemisphere, 1958-2001. Am Meteorol Soc 17:4603-4619

Cane MA (1998) Climate change - a role for the tropical Pacific. Science 282(5386):59-61. https://doi.org/10.1126/science.282.5386.59

Cassou C, Perigaud C (2000) ENSO simulated with intermediate coupled models and evaluated with observations over 1970-1998. Part II: Role of the off-equatorial ocean and meridional winds. J Climate 13: $1635-1663$

Chelton DB, Freilich MH (2005) Scatterometer-based assessment of 10$\mathrm{m}$ wind analyses from the operational ECMWF and NCEP numerical weather prediction models. Mon Wea Rev 133:409-429

Chelton DB et al (2001) Observations of coupling between surface wind stress and sea surface temperature in the eastern tropical Pacific. J Clim 14:1479-1498

Chelton DB, Schlax MG, Freilich MH, Milliff RF (2004) Satellite measurements reveal persistent small-scale features in ocean winds. Science 303(5660):978-983

Chen D (2003) A comparison of wind products in the context of ENSO prediction. Geophys Res Lett 30(3):1107. https://doi.org/10.1029/ 2002GL016121

Chu PC (1995) P-vector method for determining absolute velocity from hydrographic data. Mar Technol Soc J 29:3-14

Clarke AJ, Van Gorder S, Colantuono G (2007) Wind stress curl and ENSO discharge/recharge in the equatorial Pacific. J Phys Oceanogr 37:1077-1091. https://doi.org/10.1175/JPO3035.1

Cornillon P, Park K (2001) Warm core ring velocities inferred from NSCAT. Geophys Res Lett 28(4):575-578

Curry J et al (2004) SEAFLUX. Bull Amer Meteor Soc 85:409-424

Decker M, Brunke MA, Wang Z, Sakaguchi K, Zeng X, Bosilovich MG (2012) Evaluation of the reanalysis products from GSFC, NCEP, and ECMWF using flux tower observations. J Clim 25(6):1916-1944

Ebuchi N (1999) Statistical distribution of wind speeds and directions globally observed by NSCAT. J. Geophys. Res 104:11 393-11 403

Ebuchi N, Graber HC, Caruso MJ (2002) Evaluation of wind vectors observed by QuikSCAT/SeaWinds using ocean buoy data. J Atmos Ocean Technol 19:2049-2062

Emery WJ, Thomson RE (2001) Data analysis and methods in physical oceanography. Elsevier, New York

Foreman RJ, Emeis S (2010) Revisiting the definition of the drag coefficient in the marine atmospheric boundary layer. J Phys Oceanogr 40: $2325-2332$
Garratt JR (1977) Review of drag coefficients over ocean and continents. Mon Wea Rev 105:915-929

Godfrey JS (1989) A Sverdrup model of the depth-integrated flow for the world ocean allowing for island circulations. Geophys Astrophys Fluid Dyn 45:89-112

Gray AR, Riser SC (2014) A global analysis of Sverdrup balance using absolute geostrophic velocities from Argo. J Phys Oceanogr 44: 1213-1229. https://doi.org/10.1175/JPO-D-12-0206.1

Harrison DE (1989) On climatological monthly mean wind stress and wind stress curl fields over the World Ocean. J Clim 2:57-70

Hautala SL, Roemmich DH, Schmitz WJ (1994) Is the North Pacific in Sverdrup balance along 248N. J Geophys Res 99:16 041-16 052. https://doi.org/10.1029/94JC01084

Hu D, Wu L, Cai W, Sen Gupta A, Ganachaud A, Qiu B et al (2015) Pacific western boundary currents and their roles in climate. Nature 522:299-308. https://doi.org/10.1038/nature14504

Jiang H, Wang H, Zhu J, Tan B (2006) Relationship between real meridional volume transport and Sverdrup transport in the north subtropical Pacific. Chin Sci Bull 51:1757-1760. https://doi.org/10.1007/ s11434-006-2031-2

Jin F-F, Neelin JD (1993) Modes of interannual tropical oceanatmosphere interaction - a unified view. Part I: numerical results. J Atmos Sci 50:3477-3503

Kalnay et al (1996) The NCEP/NCAR 40-year reanalysis project. Bull Amer Meteor Soc 77:437-470

Kelly KA, Dickinson S, McPhaden MJ, Johnson GC (2001) Ocean currents evident in ocean wind data. Geophys Res Lett 28:2469-2472

Kessler WS, Johnson GC, Moore DW (2003) Sverdrup and nonlinear dynamics of the Pacific equatorial currents. J Phys Oceanogr 33: 994-1008

Kirtman BP (1997) Oceanic Rossby wave dynamics and the ENSO period in a coupled model. J Clim 10:1690-1704

Kutsuwada K, Kakiuchi A, Sasai Y, Sasaki H, Uehara K, Tajima R (2018) Wind-driven North Pacific Tropical Gyre using high-resolution simulation outputs. J Oceanogr 75:81-93. https://doi.org/10.1007/ s10872-018-0487-8

Landsteiner MC, McPhaden MJ, Picaut J (1990) On the sensitivity of Sverdrup transport estimates to the specification of wind stress forcing in the tropical Pacific. J Geophys Res 95:1681-1691

Large WG, Pond S (1981) Open ocean momentum flux measurements in moderate to strong winds. J Phys Oceanogr 11:324-336

Masumoto Y, Yamagata T (1991) Response of the western tropical Pacific to the Asian winter monsoon: the generation of the Mindanao Dome. J Phys Oceanogr 21:1386-1398

Meehl G, Gent PR, Arblaster JM, Otto-Bliesner BL, Brady EC, Craig A (2001) Factors that affect the amplitude of El Niño in global coupled models. Clim Dyn 17:515-527

Meissner T, Smith D, Wentz F (2001) A 10 year intercomparison between collocated Special Sensor Microwave Imager oceanic surface wind speed retrievals and global analyses. J Geophys Res 106:11 731-11 742

Meyers G (1980) Do Sverdrup transports account for the Pacific North Equatorial Countercurrent. J Geophys Res 85(2):1073-1075

Milliff RF, Morzel J (2001) The global distribution of the time-average wind stress curl from NSCAT. J Atmos Sci 58:109-131

Milliff RF, Large WG, Morzel J, Danabasoglu G, Chin TM (1999) Ocean general circulation model sensitivity to forcing from scatterometer winds. J Geophys Res 104:11 337-11 358

Milliff RF, Morzel J, Chelton DB, Freilich MH (2004) Wind stress curl and wind stress divergence biases from rain effects on qscat surface wind retrievals. J Atmos Ocean Technol 21(8):1216-1231

Neelin JD (1990) A hybrid coupled general circulation model for El Niño studies. J Atmos Sci 47:674-693

Qiu B, Chen S (2010) Interannual-to-decadal variability in the bifurcation of the north equatorial current off the Philippines. J Phys Oceanogr 40:2525-2538 
Qiu B, Joyce TM (1992) Interannual variability in the mid- and lowlatitude western North Pacific. J Phys Oceanogr 22:1062-1079

Rayner NA, Parker DE, Horton EB, Folland CK, Alexander LV, Rowell DP, Kent EC, Kaplan A (2003) Global analyses of sea surface temperature, sea ice, and night marine air temperature since the late nineteenth century. J Geophys Res 108(D14):4407. https://doi.org/ 10.1029/2002JD002670

Ricciardulli L, Wentz FJ (2011) Reprocessed QuikSCAT (V04) wind vectors with $\mathrm{Ku}-2011$ geophysical model function, technical report number 043011. Remote Sensing Systems, Santa Rosa, CA 8pp

Ricciardulli L, Wentz FJ (2015) A scatterometer geophysical model function for climate-quality winds: QuikSCAT Ku-2011. J Atmos Ocean Technol 32:1829-1846

Rouault M, Florenchie P, Fauchereau N et al (2003) South East tropical Atlantic warm events and southern African rainfall. Geophys Res Lett 30(5):CLI 9-1

Saunders PM (1976) On the uncertainty of wind stress curl calculations. J Mar Res 34:155-160

Simmons A, Uppala S, Dee D et al (2007) ERA-Interim: new ECMWF reanalysis products from 1989 onwards. ECMWF Newslett 110:2535

Smith SR, Legler DM, Verzone KV (1999) Quantifying uncertainties in NCEP reanalyses using high-quality research vessel observations. Proc. Second Int. Conf. on Re-Analyses, Reading. ECMWF, United Kingdom 133"C136

Spillane M, Niiler PP (1975) On the theory of strong, midlatitude winddriven ocean circulation: I. The north pacific countercurrent as a quasi-geostrophic jet. Geophys Astrophys Fluid Dyn 7(1):43-66

Storch HV, Zwiers FWD (1999) Statistical analysis in climate research. Cambridge University Press, Cambridge 484 pp

Stricherz JN, Legler DM, $\mathrm{O}_{i}{ }^{-}$Brien JJ (1997) TOGA pseudo-stress Atlas 1985"C1994: II tropical Pacific Ocean, COAPS/Florida State University, $162 \mathrm{pp}$.

Sverdrup HU (1947) Wind-driven currents in a baroclinic ocean with application to the equatorial current of the eastern Pacific. Proc Natl Acad Sci U S A 33:318-326

Thomas M, Boer D, Agatha, Johnson L, Helen, Stevens D (2014) Spatial and temporal scales of Sverdrup balance. J Phys Oceanogr 44:2644 2660. https://doi.org/10.1175/JPO-D-13-0192.1
Tozuka T, Kagimoto T, Masumoto Y, Yamagata T (2002) Simulated multiscale variations in the western tropical Pacific: the Mindanao Dome revisited. J Phys Oceanogr 32:1338-1359

Trenberth KE, Large WG, Olson JG (1990) The mean annual cycle in global ocean wind stress. J Phys Oceanogr 20:1742-1760

Wallace JM, Mitchell TP, Deser C (1989) The influence of SST on surface wind in the eastern equatorial Pacific: seasonal and interannual variability. J Clim 2:1492-1499

Wang QY, Hu DX (2006) Bifurcation of the north equatorial current derived from altimetry in the Pacific Ocean. J Hydrodyn 18(5): $620-626$

Wu R, Kinter JL III (2010) Atmosphere-ocean relationship in the midlatitude North Pacific: seasonal dependence and east-west contrast. J Geophys Res 115:D06101. https://doi.org/10.1029/2009JD012579

Wunsch C (2011) The decadal mean ocean circulation and Sverdrup balance. J Mar Res 69:417-434. https://doi.org/10.1357/ 002224011798765303

Wyrtki K (1975) Fluctuations of the dynamic topography in the Pacific Ocean. J Phys Oceanogr 5(5):450-459

Xie SP (2004) Satellite observations of cool ocean atmosphere interaction. Bull Am Meteorol Soc 85(2):195-208

Xie S-P, Liu WT, Liu Q, Nonaka M (2001) Far-reaching effects of the Hawaiian Islands on the Pacific ocean-atmosphere system. Science 292:2057-2060

Yang L, Yuan D (2016) Absolute geostrophic current in global tropical oceans. Chin J Oceanol Limnol 34:1-11

Yuan X (2004) High-wind-speed evaluation in the Southern Ocean. J Geophys Res 109:D13101. https://doi.org/10.1029/2003JD004179

Yuan D, Zhang Z, Chu PC, Dewar WK (2014) Geostrophic circulation in the tropical North Pacific Ocean based on Argo profiles. J Phys Oceanogr 44:558-575

Zhang Z, Yuan D, Chu PC (2013) Geostrophic meridional transport in tropical Northwest Pacific based on Argo profiles. Chin J Oceanol Limnol 31:656-664

Zhou H, Yuan D, Guo P, Shi M, Zhang Q (2010) Meso-scale circulation at the intermediate-depth east of Mindanao observed by Argo profiling floats. China Earth Sci 53(3):432-440

Zhou H, Yuan D, Yang L, Li X, Dewar WK (2018) Decadal variability of the meridional geostrophic transport in the upper tropical North Pacific Ocean. J Clim 31:5891-5910. https://doi.org/10.1175/ JCLI-D-17-0639.1 